\title{
Garnet-clinopyroxene and clinopyroxene geobarometry of deep mantle eclogites and peridotites
}

\author{
S.K. Simakov ${ }^{1}$ \\ ${ }^{1}$ Geological Department, St.-Petersburg University, Universitetskaya emb. 7/9, St.Petersburg, 199034, Russia \\ e-mail:simakov@vap.usr.pu.ru
}

Eclogite is one of the major xenolith types in kimberlite. The investigation of these xenoliths provides important constraints on $\mathrm{P}, \mathrm{T}$ distribution within the upper mantle and its chemical composition. A garnet-clinopyroxene barometer is proposed for mantle eclogites on the basis of the CaTs solubility in clinopyroxene coexisting with garnet on the basis of the reaction (Simakov and Taylor, 2000):
$\mathrm{Ca}_{3} \mathrm{Al}_{2} \mathrm{Si}_{3} \mathrm{O}_{12}+2 \mathrm{Mg}_{3} \mathrm{Al}_{2} \mathrm{Si}_{3} \mathrm{O}_{12} \rightarrow 3 \mathrm{CaAl}_{2} \mathrm{SiO}_{6}+6 \mathrm{MgSiO}_{3}$ Gross $\quad$ CaTs En

The barometer permits us to estimate P-T conditions for eclogite garnet-clinopyroxene assemblages, including those with sodium-rich pyroxenes in the range of $650^{\circ} \leq \mathrm{T} \leq 1700^{\circ} \mathrm{C}$ and $20 \leq \mathrm{P} \leq 70$ kbar with total uncertainty of $1 \sigma=6.1$ $\mathrm{kb}$ è $\Delta=5.3 \mathrm{kbar}$ and for peridotite ones in the range of $1050^{\circ} \leq \mathrm{T} \leq 1820^{\circ} \mathrm{C}$ and $20 \leq \mathrm{P} \leq 70$ kbar with total uncertainty of $1 \sigma=4.3 \mathrm{~kb}$ è $\Delta=3.6 \mathrm{kbar}$ (Fig.1-2). The barometer was used to determine formation conditions of eclogitic inclusions in diamonds, diamond-bearing, diamond-graphite-bearing and diamond-free eclogites and peridotites from kimberlite and lamproite pipes of Africa, Yakutia, Australia and Canada (3). From the calculations it follows that the formation of the inclusions within diamonds and diamond-bearing xenoliths mainly correspond to the region of the diamond thermodynamic stability. Diamond-graphite-bearing xenoliths lie near the graphite-diamond boundary, meanwhile graphite-bearing and diamond-free ones correspond to the field of graphite thermodynamic stability (Fig.4). The highest P-T parameters were obtained for Argyle diamond inclusions (50-90 kbar). Obtained results show that eclogite crystallization in the mantle occurs at depths from $60 \mathrm{~km}$ up to $270 \mathrm{~km}$. It is characterized by two main types of thermodynamic gradient, reflecting temperature increase with depth and lying mainly close to peridotite geotherms (Boyd, 1973).

On the basis of the Grt-Cpx versions single-mineral thermobarometers for kimberlite-derived clinopyroxene of eclogite and peridotite compositions were proposed. The accuracy of the sensors was tested on the same experimental garnet-clinopyroxene data at experimental temperatures with total uncertainties of $1 \sigma=3.1-5.0 \mathrm{kbar}$. The eclogite version was used to determine P-T conditions of omphacitic inclusion formation in the alluvial diamonds from Venezuela and Guinea (Fig.5), and from Ñanadian (Fig.3) and Udachnaya diamonds. The peridotite sensors were used to determine P-T conditions of clinopyroxene inclusion formations in Ghana and Tanzania diamond (Fig.6). 

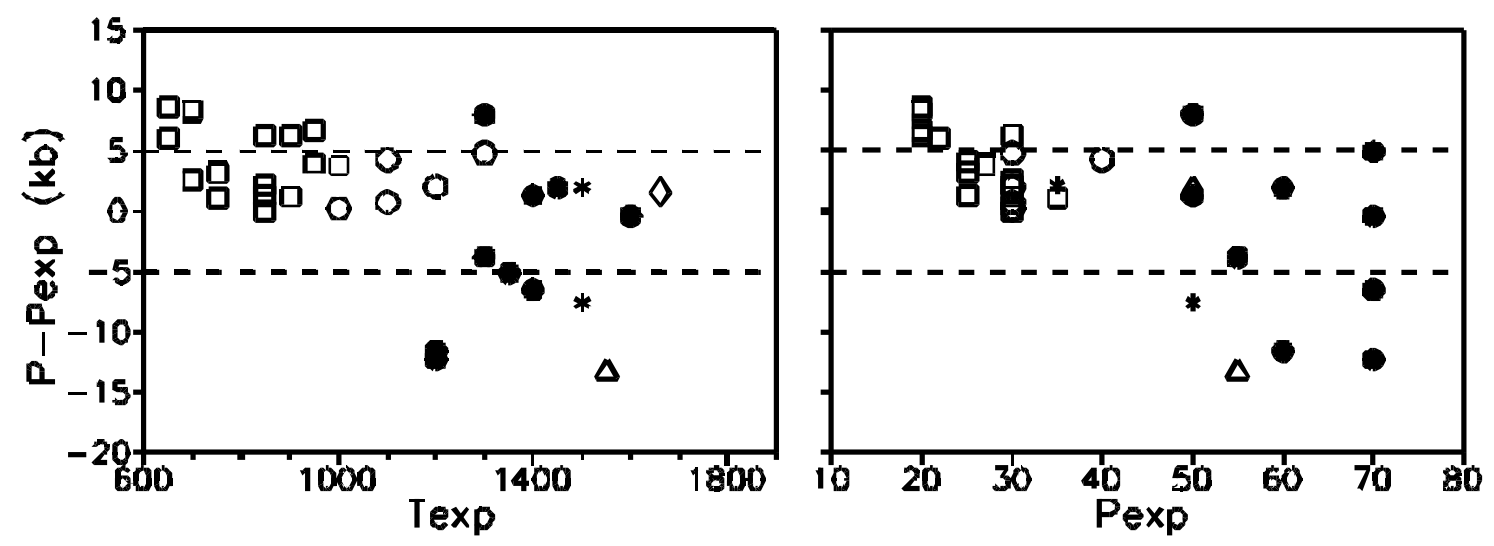

Fig.1. Difference between calculated and experimental pressures (P-P(exp)) (in kbars) for "eclogite" version of Grt -Cpx barometer. The experimental data were taken from: * - Genshaft et al. (1986); x- Poly (1993); - Yaxley and Green (1994); $\diamond$ - Putirka (1998); $\Delta$ - Kato et al. (1989); + - Brey and Green (1977); Adam (1990), ${ }^{\circ}$ - Raheim and Green (1974), • Mitchell, 1995; Edgar and Mitchell, 1997.
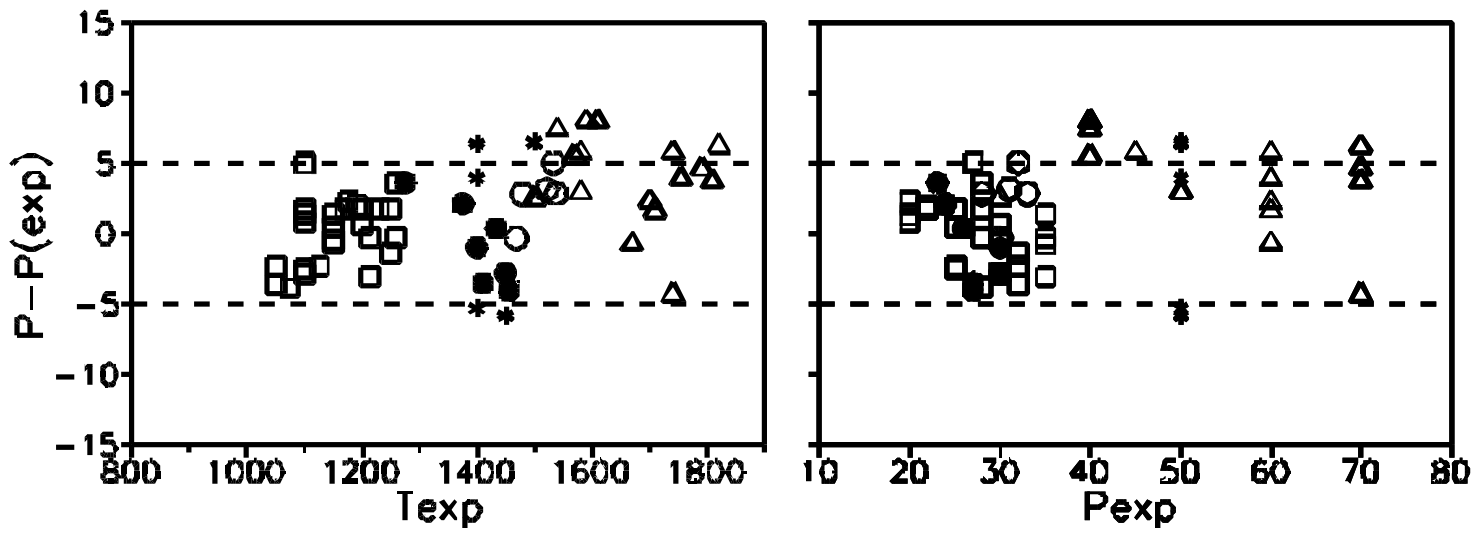

Fig.2. Difference between calculated and experimental pressures (P-P(exp)) (in kbars) for "peridotite" version of Grt -Cpx barometer. The experimental data were taken from: * -Ryabchikov et al., (1993); - Taylor (1998); $\diamond$ - Brey and Kohler (1990); $\Delta$ - Walter (1998); + - Sekine and Wyllie (1982); Sweeney (1994); • Jonston (1986), ${ }^{\circ}$ Robinson and W ood (1998). 


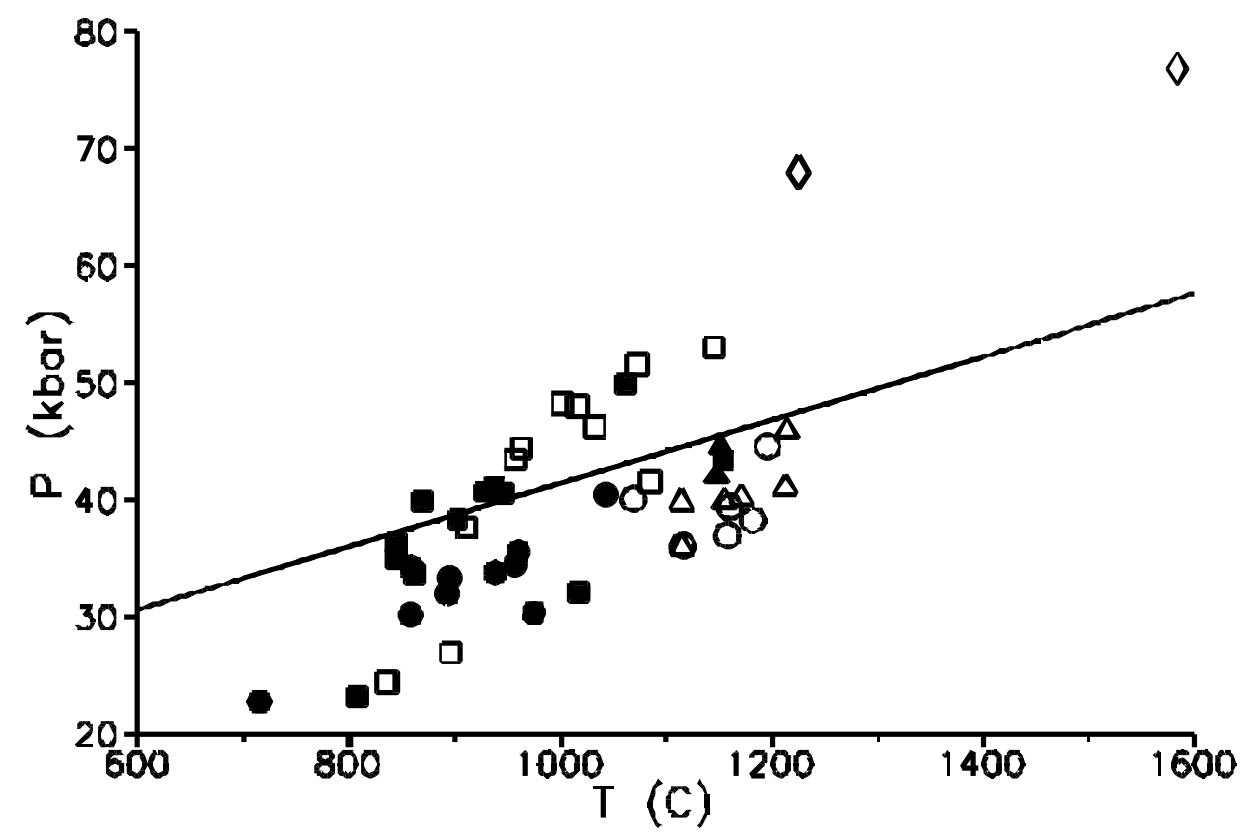

Fig.3. P-T plot relative to the diamond-graphite transition curve (Bundy et al, 1961) for kimberlite xenoliths by Git-Cpx barometer (closed circles - coarse-grained peridotites, open circles - porphyroclastic non-disrupted peridotites; open triangles - megacrystalline pyroxenites, closed triangles - Ilm-Grt werlite-clynopyroxenites, anysotropic eclogites, closed squares - massive eclogites) and for eclogite diamond inclusions (diamonds) by Cpx barometer. For temperature estimation the garnet-clinopyroxene thermometer of Ellis and Green (1979) was used, analyses for the calculations were taken from: Davies et al. (1999); Kopylova et al. (1999).

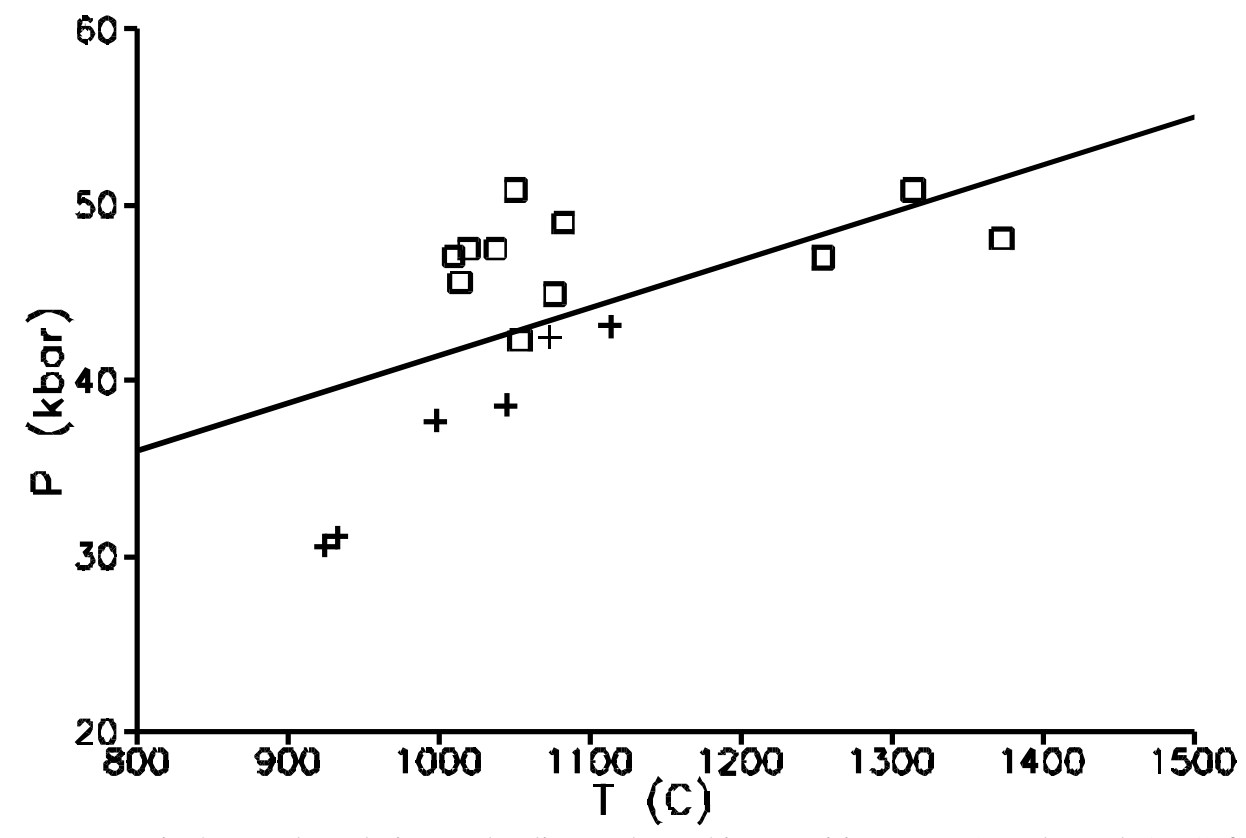

Fig.4. P-T plot relative to the diamond-graphite transition curve (Bundy et al, 1961) for Orapa, Roberts Victor and Sloan diamond-graphite-bearing (squares) and graphite-bearing (crosses) eclogites. Analyses for the calculations were taken from: Hatton and Gurney (1979); McCandless and Collins, 1989; Robinson et al., (1984); Shee and Gurney (1979). 


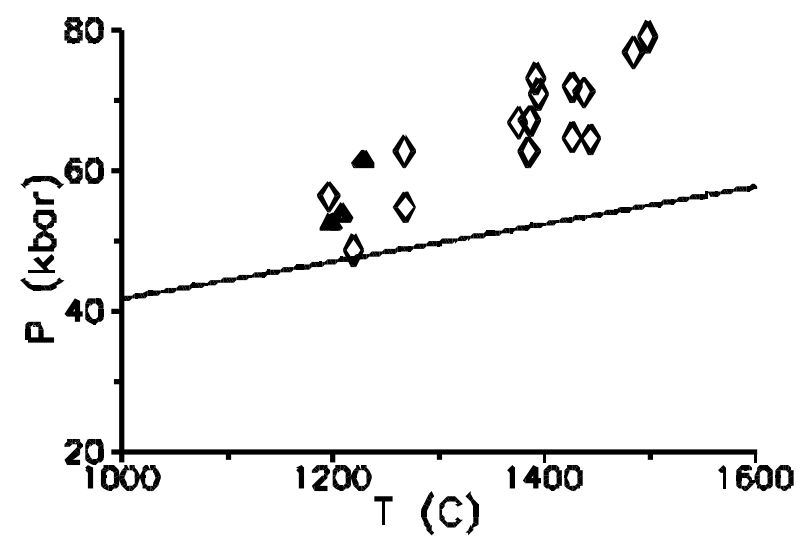

A

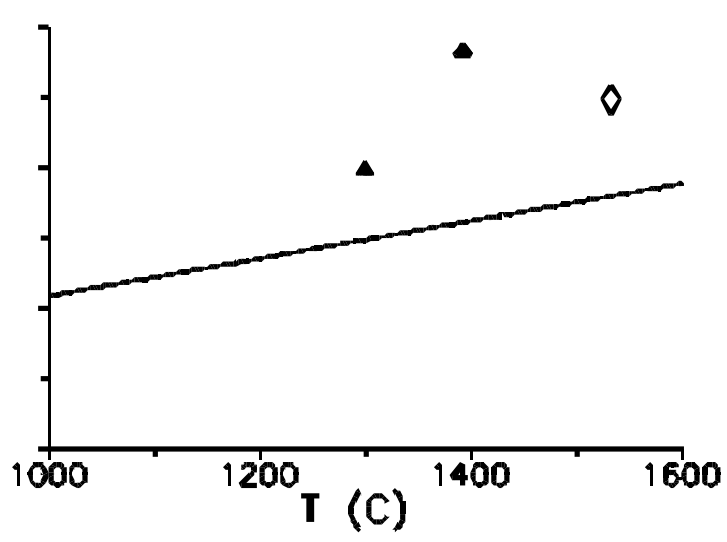

B

Fig.5. PT plot relative to the diamond-graphite transition curve (Bundy et al, 1961) for eclogite diamond inclusions from Venezuela (A) and Guinea (B). Temperature was calculated by Ellis and Green (1979) thermometer, pressure - by Grt-Cpx (closed triangles) and by single Cpx (diamonds) barometer versions. Analyses for the calculations were taken from: Kaminsky et al. (2000), Stahel et al. (2000).

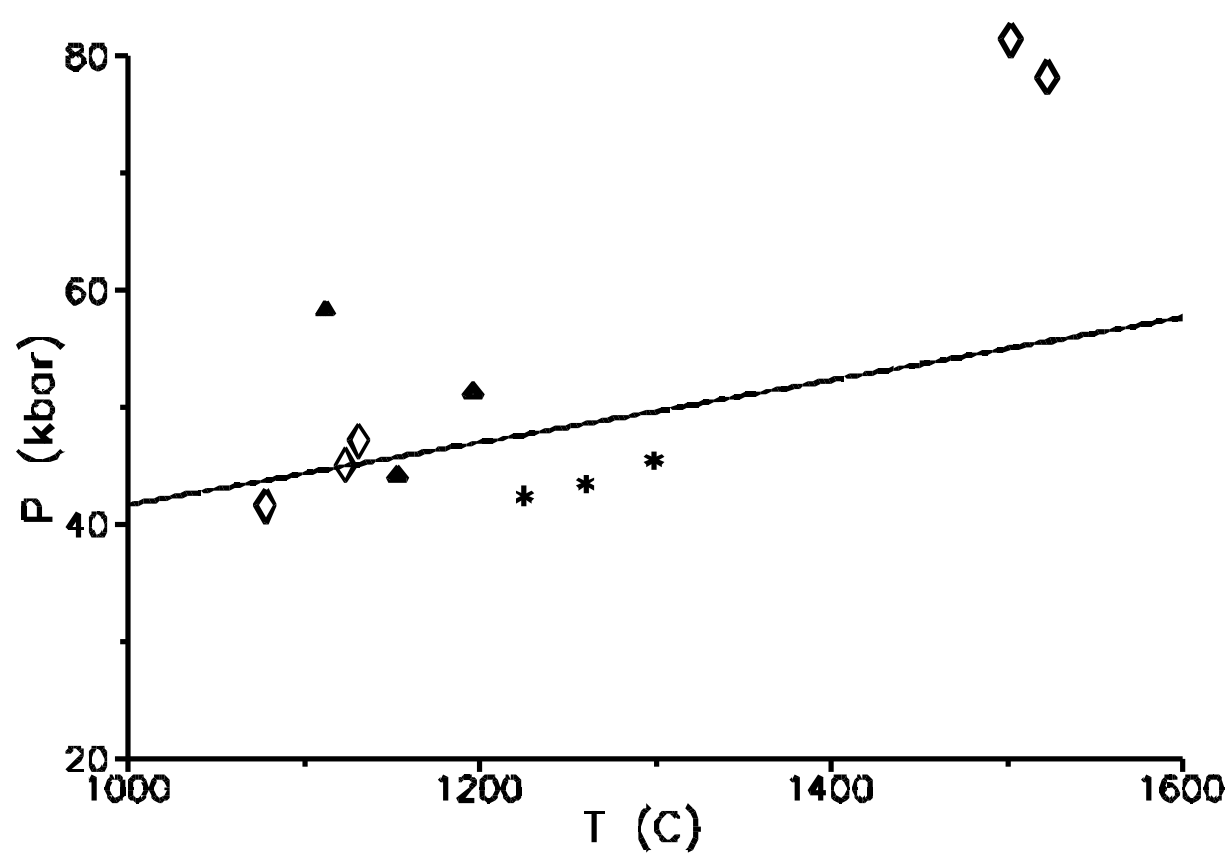

Fig.6. P-T plot relative to the diamond-graphite transition curve (Bundy et al, 1961) for peridotite Grt-Cpx and single Cpx diamond inclusions from Ghana and Tanzania (diamonds and closed triangles correspondingly) and for Cpx megacrystes from Kao and Lesotho pipes (*). For Grt-Cpx assemblages the garnet-clinopyroxene barometer was used, for Cpx - clinopyroxene barometer, analyses for the calculations were taken from: MacGregor (1979); Stahel et al. (1997, 1998, 1999). 